\title{
The Relationship Between Personality Types and Occupational Stress of Teachers in Selected Private Higher Education Institutions of Addis Ababa
}

\author{
Dargie Yemane Hadush \\ Addis Ababa University, College of Education and Behavioral Studies, School of Psychology
}

\begin{abstract}
The objective of this study was to examine the relationship between personality types and occupational stress of teachers in private higher education institutions of Addis Ababa. The study employed correlational research design and the lottery method was used to select 154 participants. Two instruments were used which were Big Five Inventory (BFI) and Teachers Occupational Stress Scale (TOSS). To analyze the collected data, both descriptive and inferential statistics were applied. The findings of the study revealed that $30.3 \%$ of the teachers experienced a low level of stress, $42.8 \%$ experienced moderate levels of stress, and $26.9 \%$ experienced high levels of occupational stress. Female teachers score significantly higher occupational stress $(\mathrm{M}=57.74, \mathrm{SD}=11.24)$ as compared to the males $(\mathrm{M}=47.76, \mathrm{SD}=5.24)$ and the t-test yielded a statistically significant difference between the mean scores of male and female teachers on the overall occupational stress scale $(\mathrm{t}=-4.491, \mathrm{df}=143$, $\mathrm{P}=.000, \alpha=0.05)$. The result also indicated that there is a significant negative correlation between occupational stress and conscientiousness $(\mathrm{r}=-0.442, \mathrm{p}<0.05)$, agreeableness and occupational stress $(\mathrm{r}=-0.371, \mathrm{p}<0.05)$, and extraversion and occupational stress $(\mathrm{r}=-0.347, \mathrm{p}<0.05)$. However, there is no statistically significant relationship between openness and occupational stress of teachers $(\mathrm{r}=-0.002, \mathrm{p}>0.05)$. There was a significant positive correlation between neuroticism and the occupational stress of teachers $(r=0.211, p<0.05)$. Moreover, the results revealed that personality has a statistically significant negative link with occupational stress $(\mathrm{r}=-0.338$, $\mathrm{p}<0.05)$.
\end{abstract}

Keywords: Personality Types, Occupational Stress

DOI: $10.7176 / \mathrm{JEP} / 12-4-03$

Publication date: February $28^{\text {th }} 2021$

\section{INTRODUCTION}

Personality traits can play a significant role within the effectiveness of organization performance and recent studies have reported that many personality traits predict specific work-related behaviors, stress reactions, and emotions well under conditions (Zamir, Hina, \& Zamir, 2014). However, some individuals are more vulnerable to stressful situations than others. For example, Neuroticism is recommended to be linked to individual differences in emotional reactivity to stress (Zamir, Hina, \& Zamir, 2014).

Personal elements of an individual such as evaluation of stressful events, the selection and efficiency of dealing strategies, and the impact of stress on well-being may increase or minimize the effect of stress (Ozutku \& Altindis, 2011). Some individuals easily exposed to stress such as neuroticism personality but others like individuals with openness to experience personality and agreeableness are less exposed to stress (Ozutku \& Altindis, 2011).

Personality can be defined as an enduring and stable characteristic of an individual which makes him unique. It is the total accumulation of an individual's unique characteristics' that anticipated being consistent and stable across situations (Asmawati, Fatimah, Norhayati, Nor Ba'yah, \& Roseliza, 2014). They further considered personality, as a combination of an individual's belief, attitude, emotion, and behavior which relatively assumed to be stable and make him/her unique (Asmawati et al., 2014).

Stress could be a condition of strain on one's emotion's thought processes and wellbeing. When it's excessive, it can threaten one's ability to deal with the environment (Saravanan \& MuthuLakshmi, 2017). As a result of this excessive pressure, the employees develop certain symptoms of stress like becoming nervous and worry that affects his/her performance. Stress is the general term applied to the pressures people feel in life (Saravanan \& MuthuLakshmi, 2017).

In the past two decades' educational psychologists and social researchers gave much emphasis to the issue of stress (Popoola \& Ilugbo, 2010). It appears to be an unavoidable characteristic within the lives of human beings and affects the day to day living. It occurs when there is a discrepancy between the individual's interest, capability, and demands of the working environment (Pithers \& Soden, 2006).

Compared to other professions, the teaching profession is at high risk for higher levels of occupational stress (Gurpreet, 2009; Aftab, 2013; Alemu, Teshome, Kebede \& Regassa, 2014; Gebrekirstos, 2015; Baraza, Simatwa, \& Gogo, 2016). According to these researchers, the great stressors for teachers include student misbehaviors, work overload, uncomfortable working environment, delay and non-payment of salaries, time 
pressure, parent's insults, and assaults, lack of motivation of students, teachers' competence and poor relationships with administration and colleagues.

Stress costs plenty within the teaching profession but little attention was given than other occupations (Gurpreet, 2009). The prices of stress within the teaching set are high in terms of wasted training for those that leave their jobs and in terms of the psychological and physical effects upon those that stay. A stressed teacher is also no longer remains a role model for the young generation (Gurpreet, 2009).

According to Chan, Chen, and Chong (2010) in their study in Hong Kong of work stress of teachers from primary and secondary schools, the results indicated that compared with one year and five years ago, $91.6 \%$ and $97.3 \%$ of the responding teachers reported a rise of perceived stress level, respectively. The study further revealed that heavy workload; time pressure, education reforms, external school review, pursuing further education and managing students' behavior and learning were the foremost frequently reported sources of occupational stress. However, the study found that there is no statistically significant difference between male and female teachers in experiencing occupational stress $(\mathrm{p}>0.05)$.

A study conducted by Popoola and Ilugbo (2010) found that all teachers experience (100\%) occupational stress and only they differ in the level of stress they experience. The poor interaction of teachers with students and their parents triggers occupational stress in teachers (Ipek, Akcay, Atay, Berber, Karalik, \& Yilmaz, 2018).

The link between personality types and occupational stress has been a frequently studied research topic in numerous disciplines including educational settings (Dumitru \& Cozman, 2012). It helps to know how certain individuals function properly while others exposed to stressful stimuli (Dumitru \& Cozman, 2012). Most of the time a competitive person, aggressive, and hostile personality type is more experienced occupational stress. Anxious people can be more stressed at work or frustrated and dissatisfied when things don't go consistent with their plan (Mmaduakonam \& Ifeoma, 2015).

Individuals with different personality types differ in their perception of the effects and consequences of stress (Ozutku \& Altindis, 2011). A personality characteristic of an individual affects his/her view and the way how they experience stress. The working environment also affects the individual's capacity of managing stress. This asserts that occupational stress is not a characteristic of either the environment or individual but it is the result of the interaction between an individual and the environment (Ozutku \& Altindis, 2011).

In developing countries, like Ethiopia, teachers experience a lot of challenges and stressors that affect their performance (Elleni, 2017). This results in lower quality education and affects the educational environment productivity. A study conducted by Gebrekirstos (2015) revealed that all teachers (100\%) experienced a high level of occupational stress. Studies conducted by Alemu, Teshome, Kebede, and Regassa (2014) and Elleni (2017) also yielded similar results.

The rationale for conducting this research is that my observation and familiarity I have had with the problem of teachers' stress and boredom working on different levels of educational institutions. As all of we might know that teachers are the main pillars in educating and molding a generation of a given country, apart from that neither they are given due attention nor free from mental pressure for being a teacher. As of my exposure to the area, the level of stressor situation is seemingly high in private higher institutions. I worked as a teacher in a private school and had the opportunity to discuss with different teachers about the nature and prevalence of occupational stress. I have observed the problem while we discuss the issue of teaching in different circumstances. Thereafter, it has always been a puzzle for me to know the issue from a scientific standpoint whether the problem stems from the individual personality type or external factors currently working as a teacher. Accordingly, the researcher is driven by all these reasons in mind to explain the relationship between personality types and occupational stress of teachers of private higher education institutions in Addis Ababa.

\section{METHODOLOGY}

The study employed a correlational research design. Correlation design helps to examine the magnitude, degree, and direction of the relationship between the variables. The study was conducted in Addis Ababa city administrations of private higher education institutions. The researcher selected this site for its familiarity and proximity with the study site. The target population of this study was teachers who are currently working at Private Higher Education Institutions of Addis Ababa. There are 85 private higher education institutions in Addis Ababa (HERQA, 2012). Practically, it is difficult to include all the target populations in the study. The researcher employed a lottery method of the simple random sampling method to select 9 private higher educations.

Lottery method is most of the time applicable when the population and sample size involved are relatively small i.e., fewer than 100 in the population and fewer than 50 in the sample (Kothari, 2004). Due to this reason the researcher used the lottery method to select the institutions. Even if it is difficult to precisely determine how a sample could be representative of a population, Kothari (2004) recommend that $10 \%$ of the defined population is sufficient. In this study, the researcher selected $9(10 \%$ of 85$)$ PHEIs as a representative of the total 85 institutions. The researcher wrote the names of all colleges on pieces of papers and drawn 9 private higher 
education institutions as a sample.

The researcher employed simple random sampling to select participants from each nine private higher education institutions. The researcher gave an equal chance of selection and tries to avoid bias based on participants' socio-demographic factors. Every participant of the study had the same probability of being chosen. The reason why the researcher used simple random sampling is each participant will have an equal chance of selection. As a result of this, it is easy to generalize the result of the study to the target population. This helps to make an inference from the sample to the general population.

\section{Sample size determination}

The total target populations of the nine selected private higher education institutions were 250 . Based on Yamane (1967) formula, cited in Meaza (2018), the researcher used a sample calculating formula from the total population. Yamane's (1967) formula is applicable for determining sample size if two conditions are met. $1^{\text {st }}$, the population must be known and $2^{\text {nd }}$ the population must be finite. Based on this justification and its simplicity the researcher employed this scientific formula for determining sample size out of 250 total populations. By employing Yamane's (1967) scientific sample size determination formula each private higher education had an equal chance of selection based on their total number of employees.

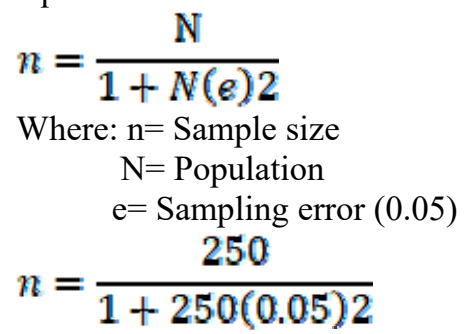

Therefore, based on the calculation the total sample size was 154 . The total teachers in each private higher education were not the same across the nine colleges. So, the following formula was used to calculate the number of samples from each selected private higher education institution.

$$
\begin{gathered}
\mathrm{n} !=\frac{\mathrm{nN} !}{\mathrm{N}}=\text { Where, } \mathrm{n} !=\text { total number of sample size in each private higher education } \\
\mathrm{n}=\text { total number of sample size } \\
\mathrm{N} !=\text { total number of population in each private higher education } \\
\mathrm{N}=\text { total number of population }
\end{gathered}
$$

Table 1: Name of institutions and their respective sample size

\begin{tabular}{lcc}
\hline Institutions & Total population & Sample size \\
\hline & & 15 \\
Gage College & 25 & 38 \\
St. Marry University & 60 & 23 \\
Damat College & 35 & 18 \\
Addis Ababa Medical and Business College & 30 & 15 \\
Universal Technology College & 25 & 6 \\
International Leadership Institute & 10 & 12 \\
Africa Beza College & 20 & 15 \\
Universal Medical College & 25 & 12 \\
Micro Link Information and Technology College & 20 & $\mathbf{1 5 4}$ \\
\hline Total & $\mathbf{2 5 0}$ & \\
\hline The data collection instrument employed in this study was a structured questionnaire. The questionnaire \\
consists of three parts. The first part is about socio-demographic characteristics (sex, age, work experience, and \\
academic qualification of participants). The second part is the big five scales which measure the five personality \\
dimensions or types of individuals. The third part is the stress scale which is the Teachers Occupational Stress \\
Scale (TOSS). These two instruments will be discussed briefly below.
\end{tabular}

\section{The Big Five Inventory (BFI)}

There are various scales (John Holland's job-personality questionnaires (1971); Eysenck Personality InventoryRevised (EPQ-RS (1992) developed to measure the personality types of individuals (Costa \& McCrae, 2017). But the Big Five Inventory (BFI) is a comprehensive assessment inventory and applicable in different cultures (Costa \& McCrae, 2017). It is an efficient and flexible assessment tool that measures the five personality dimensions.

The instrument is a 44-item scale measuring the five personality traits of extraversion, agreeableness, 
neuroticism, conscientiousness, and openness. The scale was developed by John \& Srivastava (1999). The 44 items have five subscales and the extraversion type contains 8 items, agreeableness has 9 items, conscientiousness 9 items, neuroticism has 8 items, and openness with 10 items. The instrument uses a 5-point Likert scale and the pattern of scoring response from Strongly Disagree was given a worth of $=1$, Disagree a worth of $=2$, Undecided a worth of $=3$, Agree worth of $=4$, and Strongly Agree worth of $=5$. From the total 44 items, 14 Items were score reversely. The Cronbach alpha for each dimension was .88 for extraversion, .79 for agreeableness, .82 for conscientiousness, .84 for neuroticism, and .81 for openness. The Cronbach alpha for the total score was .83.

Examples of items from the instrument include (a) I see myself as someone who is talkative. (b) I see myself as someone helpful and unselfish with others. (c) I see myself as someone relaxed, handles stress well. (d) I see myself as someone worried a lot. (e) I see myself as someone who has an active imagination. (f) I see myself as someone who remains calm in tense situations.

\section{Teachers Occupational Stress Scale (TOSS)}

Before selecting teachers occupational stress scale the researcher investigated different scales that measure teachers' occupational stress like that of (Clark, 1980, Fimian \& Santoro, 1983; Boyle et al., 1995). Even though these instruments measure the occupational stress of teachers the questions did not fit with the researchers' focus of the research area. And the scales are not shorter and easy to administer. Because of these reasons the researcher considered teacher's occupational stress developed by Aftab (2013) as appropriate for this study.

Teachers' Occupational Stress Scale (TOSS) measure teachers' occupational stress levels. It was developed by Aftab (2013) and has 20 questions. The instrument uses a 5 - point Likert scale and the pattern of scoring response category, 'strongly agree' was given a rate of 5, 'agree' a rate of 4, 'undecided' a rate of 3 , 'disagree' a rate of 2 and 'strongly disagree' a rate of 1 . Based on the results of pilot testing 2 items were deleted from the original instrument. The instrument has 18 negatively worded items. For instance, (i) I am bored with my job (ii) My opinions are not appreciated by my principal (iii) My job does not satisfy me any longer.

The teachers' occupational stress score is calculated by adding the individual scores of all the items together where the possible range can be between 18-90, with a mean of 54. A low score on the TOSS indicates a low level of stress or high satisfaction toward the teacher's job, and a high score on TOSS indicates a high level of stress or low satisfaction toward the teacher's job.

Teachers' occupational stress levels are categorized into low- (18-41), moderate (42-66), and high (67-90) levels of stress following stress scores obtained. The scale has split-half reliability of 0.83 . The inner consistency coefficient determined by the Cronbach alpha correlation is 0.92 . The scoring table for the occupational stress level is stated in table 2 as follows:

Table 2: Scoring table for the occupational stress inventory for teachers

\begin{tabular}{lc}
\hline Label & Range of scores \\
\hline Low OS & $18-41$ \\
Moderate OS & $42-66$ \\
High OS & $67-90$ \\
\hline
\end{tabular}

The categorization of the current occupational stress level of the private higher education institutions teachers was accompanied by using the scoring system which was established by the developer of the scale and some modifications were made based on the result of pilot testing.

After gathering and collecting data the next important step is analyzing the data. The collected data was processing using SPSS (version 25). Data collected related to socio-demographic aspects of participants and participant's occupational stress level were analyzed using descriptive measures of frequency and percentage. The data collected on the link between personality dimension and OS were analyzed using the Pearson-product moment correlation. To examine the significant gender difference in the occupational stress levels of teachers $\mathrm{T}$ test was used. The results were reported and presented in tables.

\section{RESULTS AND DISCUSSION}

\section{- Results}

A total of 154 questionnaires were distributed to participants and $145(94.2 \%)$ were properly filled and returned. Out of the total number of respondents who completed the questionnaire, $118(81.4 \%)$ were male and $27(18.6 \%)$ were female teachers. It is evident from the result shown that there are more male than female teachers working in private higher education institutions (PHEIs) of Addis Ababa.

With regard to the age distribution, the data show that $56(38.6 \%)$ of the respondents were in the age category $20-30$ years followed by $43(29.7 \%)$ respondents who belonged to the age category of $31-40$ years. The least number of respondents $22(15.1 \%)$ failed in the age range of 41-50 years old followed by $24(16.6 \%)$ in the age range of 51-60 years.

The data depict that the highest percentage $(\mathrm{N}=68,46.9 \%)$ of academic qualification of teachers included in 
the study was BA/BSc Degree followed by a Master Degree consisting of 56 (38.6\%). The remaining respondents $(\mathrm{N}=21,14.5 \%)$ had a Diploma.

The data gathered also revealed that $40(27.6 \%)$ respondents have work experience between $0-5$ years followed by $39(26.9 \%)$ respondents who have 6-10 years of work experience. $31(21.6 \%)$ respondents reported having served for more than 15 years while 35 (24.1\%) respondents served for about 11-15 years.

Categorization of the Level of Occupational Stress of the Teachers

The analysis of the data regarding the level of occupational stress experienced by PHEIs teachers yielded that 40 $(30.3 \%)$ and $62(42.8 \%)$ teachers have low and moderate levels of occupational stress, respectively. The prevalence of occupational stress among teachers of PHEIs included in this study is $27 \%$. In this study, 39 $(26.9 \%)$ teachers experienced high occupational stress.

The mean occupational stress scores of the respondents were 48.6 with a standard deviation of 11.09 . The minimum and maximum scores obtained by the respondents were 29 and 75, respectively. The data presented show that nearly half of the teachers experienced a moderate level of occupational stress.

\section{Gender difference in occupational stress}

To test whether there is a significant mean difference between a male and female teacher's in experiencing OS or not, the researcher carried out an independent samples t-test. The mean occupational stress scores of male and female teachers were found 47.76 and 57.74 with SDs of 11.24 and 5.24 respectively. When the means of two groups compared, the t-test yielded a statistically significant difference between the mean scores of male and female teachers on the overall occupational stress scale $(t=-4.491$, $\mathrm{df}=143, \mathrm{P}=.000, \alpha=0.05)$. More specifically, female teachers score significantly higher occupational stress as compared to males.

Relationship between personality types and occupational stress of teachers

The relationship between personality types and occupational stress of teachers was investigated using a twotailed Pearson correlation analysis. These findings are presented in Table 3 below.

Table 3: Correlation matrix of personality types and occupational stress

\begin{tabular}{|c|c|c|c|c|c|c|}
\hline Variables & 1 & 2 & 3 & 4 & 5 & 6 \\
\hline 1. Extraversion & & & & & & \\
\hline 2. Agreeableness & $\begin{array}{l}0.237^{* *} \\
.004\end{array}$ & - & & & & \\
\hline 3. Conscientiousness & $\begin{array}{l}0.547^{* *} \\
.000\end{array}$ & $\begin{array}{l}0.489^{* *} \\
.000\end{array}$ & - & & & \\
\hline 4. Neuroticism & $\begin{array}{l}-0.126 \\
.132\end{array}$ & $\begin{array}{l}-0.298^{* *} \\
.000\end{array}$ & $\begin{array}{l}-0.241 * * \\
.003\end{array}$ & - & & \\
\hline 5. Openness & $\begin{array}{l}0.009 \\
.912\end{array}$ & $\begin{array}{l}0.048 \\
.569\end{array}$ & $\begin{array}{l}0.045 \\
.588\end{array}$ & $\begin{array}{l}-0.038 \\
.649\end{array}$ & - & \\
\hline 6. OS & $\begin{array}{l}-0.347^{* *} \\
.000\end{array}$ & $\begin{array}{l}-0.371 * * \\
.000\end{array}$ & $\begin{array}{l}-0.442 * * \\
.000\end{array}$ & $\begin{array}{l}0.211^{*} \\
.001\end{array}$ & $\begin{array}{l}-0.002 \\
.976\end{array}$ & - \\
\hline
\end{tabular}

$* *$. Correlation is significant at the 0.01 level (2-tailed).

*. Correlation is significant at the 0.05 level (2-tailed).

Table 4 above shows the correlation between the dimensions of personality and the occupational stress scores of teachers. As it has been clearly shown in the Table 3 above, the extraversion $(r=-0.347, p=.000)$, agreeableness $(r=-0.371, p=.000)$, and conscientiousness $(r=-0.442, p=.000)$ personality dimensions had a statistically significant link with occupational stress of teachers. The result of the study showed that there is a positive correlation between neuroticism and occupational stress of teachers $(r=0.211, p<0.05)$.

The finding of the study failed to reveal a statistically significant relationship between openness $(r=-0.002$, $\mathrm{p}=.976$ ) and occupational stress. The analysis further determined the relationship between overall personality score and occupational stress. The analysis yielded a statistically significant moderate negative association between personality and occupational stress in PHEIs of Addis Ababa $(\mathrm{r}=-0.338, \mathrm{p}=.000, \alpha=0.05)$. This implies that personality and occupational stress have an inverse relationship and as an overall score of personality increase the score in occupational stress decrease and vice versa.

Regression analysis of personality types and occupational stress

The researcher conducted a regression analysis to determine which personality dimension (i.e. extraversion, agreeableness, conscientiousness, neuroticism, and openness) influence and predict occupational stress of teachers in PHEIs of Addis Ababa.

Table 4: Regression analysis: Model Summary

\begin{tabular}{lcccc}
\hline Model & $\mathrm{R}$ & $\mathrm{R}$ Square & Adjusted Square & $\mathrm{R}$ Std. Error of the Estimate \\
\hline 1 & $.501^{\mathrm{a}}$ & .251 & .224 & 9.76667 \\
\hline a. Predictors: (Constant), extraversion, neuroticism, agreeableness, conscientiousness, openness to experience \\
As can be seen from the above Table 4, the R-square value for the regression model is .251. This indicates \\
that personality types (openness, extraversion, neuroticism, agreeableness, and conscientiousness) in this study
\end{tabular}


explain $25.1 \%$ of the variation in experiencing occupational stress of teachers.

Table 5: ANOVA Result

\begin{tabular}{cccccc}
\hline Model & Sum of Squares & Df & Mean Square & F & Sig. \\
\hline Regression & 4437.225 & 5 & 887.445 & 9.304 & .000 \\
Residual & 13258.913 & 139 & 95.388 & - & - \\
Total & 17696.138 & 144 & & - & -
\end{tabular}

As shown in the ANOVA table (Table 5) the sample data provide sufficient evidence to conclude that the regression model was well fit. In other words, it can be concluded that personality types (i.e. openness, extraversion, neuroticism, agreeableness, and conscientiousness) predicted teacher's occupational stress significantly.

Table 6: Regression coefficients of personality variables

Coefficient's ${ }^{\mathrm{a}}$

\begin{tabular}{|c|c|c|c|c|c|}
\hline \multirow[b]{2}{*}{ Model } & \multicolumn{3}{|r|}{$\begin{array}{l}\text { Standardized } \\
\text { Coefficients }\end{array}$} & \multirow[b]{2}{*}{$\mathrm{T}$} & \multirow[b]{2}{*}{ Sig. } \\
\hline & B & Std. Error & Beta & & \\
\hline (constant) & 96.924 & 13.249 & & 7.618 & .000 \\
\hline Extraversion & -.458 & .253 & -.159 & -1.808 & .073 \\
\hline Agreeableness & -.670 & .300 & -.193 & -2.238 & .027 \\
\hline Conscientiousness & -.756 & .305 & -.244 & -2.483 & .014 \\
\hline Neuroticism & .258 & .264 & .076 & .977 & .330 \\
\hline Openness & .052 & .141 & .027 & .369 & .713 \\
\hline
\end{tabular}

a. Dependent Variable: OS

As shown in the Table 6 above, the regression analysis of the study revealed that agreeableness $(\beta=-0.193$, $\mathrm{t}=-2.238, \mathrm{p}=0.027)$ and conscientiousness $(\beta=-0.244, \mathrm{t}=-2.483, \mathrm{p}=0.014)$ personality dimensions significantly predicted occupational stress of teacher's in private higher education institutions of Addis Ababa. Specifically, the unstandardized beta (B) represents the slope of the line between personality types and occupational stress. For instance, one-unit increase in extraversion results in 0.458 units decrease in the level of occupational stress. The results in Table 6 above also display that neuroticism, extraversion, and openness to experience personality dimensions did not predict occupational stress significantly.

\section{- Discussion}

This section elaborated on the research findings, examined how the research questions were addressed and discussed the implications of the results. The major findings of this study are presented in concerning the previously identified research questions in chapter one. The findings of these questions are indicated below:

\section{General pattern of occupational stress of PHEIs teachers}

Occupational stress is a universal phenomenon that is being progressively used in the workplace. The reason is that human beings have many biological, psychological, and social needs. When these needs are not satisfied, they experience stress (Aftab, 2013). The findings of the current study revealed that the majority of the teachers' in PHEIs of Addis Ababa experienced a moderate level of occupation stress. The result of the study also revealed that female teachers experienced more occupational stress compared to male teachers.

The results obtained in the present study are supported by other investigations. Khurshid, Butt, and Malik (2011) reported that public sector university teachers' reported experiencing a moderate to high-level occupational role stress, whereas the private sector university teachers reported mild to moderate role stress. This means teachers whether in government or private institutions experience stress. What may vary are the stress levels. The possible explanations suggested by the researcher might be teachers encounter many overload tasks like lack of teaching materials, counselling a large number of students, poor salary, family issues, workload, and financial resources.

The current finding is similar to the results obtained by Ahghar (2008) and who reported that $40.2 \%$ of the teachers showed occupational stress at levels below the mean value, $26.6 \%$ at the mean level, and $13.42 \%$ at the level higher than the mean. The findings are also in line with the findings of Raza (2012) and found that a moderate level of stress is perceived by university teachers.

Similar results were found in a study conducted by Dahiya (2015) in the issue of occupational stress and personality traits in the Indian Manufacturing Sector. The finding of the study shows that the large scale prevalence of occupational stress among blue-collar employees in the Indian manufacturing sector as a majority of the respondents i.e., $82.4 \%$, participated in the survey reported that perceived level of occupational stress is average and above. Among these, the percentage of respondents with a high level of occupational stress is $46.3 \%$, while the rest $36.1 \%$ of respondents are those for whom the average level of occupational stress has been recorded. The percentage of respondents with a low level of occupational stress is the lowest (17.6\%).

Gebrekirstos (2015) in his study of occupational stress among secondary school teachers and their coping strategies in the central zone of the Tigray region found that all teachers $(100 \%)$ experienced a high level of 
occupational stress.

\section{Mean difference between male and female teachers in experiencing occupational stress}

The demographic characteristics of participants indicate that there is still a huge gap between male and female teachers in private higher education institutions. This implies that even if the Ministry of Education and Addis Ababa Education Bureau are trying their best to increase the number of female-teachers in PHEIs, the gap is not yet narrowed.

The result of the current study found that female teachers experienced more occupational stress compared to male teachers. Similar findings were reported by Anbu (2015). He found that female teachers experienced more occupational stress than male teachers in higher secondary school institutions. The reason he suggested by Anbu (2015) was that female teachers apart from guiding the failure school students, have to look after their family members, they were not able to allocate equal weightage to work as well as family environment, hence this results in enhanced stress level.

A study conducted by Agai-Demjaha, Bislimovska, \& Mijakoski, (2015) found that female teachers showed a high level of occupational stress compared with male teachers. Other various studies (Baraza, Simatwa, \& Goge, 2016; Saravanan \& MuthuLakshmi, 2017; Gezae, Wallegn, Getahun, \& Ararso, 2018) also found consistent results with the finding of the current study and conclude that female experienced high level of occupational stress than male teachers. The reason they suggest in the finding was female teachers additionally involved more in domestic activities beyond their academic responsibilities.

The current finding is inconsistent with the findings of Aftab (2013), in her study of the relationship among teachers' occupational stress, job satisfaction, work values, and pupil ideology of Aligarh Muslim University reported that greater percentage of female teachers' $(54.74 \%)$ experience less stress toward their occupation than their male colleagues (39.50\%). Females, thus, were observed to come across less stressful experiences in secondary schools.

The present finding of the study is also contrary to the study of Jude (2011) and Hasan (2014). They discovered that there is no significant difference between male and female teachers in displaying occupational stress. However, the result is confirmed in the study conducted by Nagra and Arera (2013). They found that female teachers are highly exposed and experienced a high level of occupational stress than male teachers.

To the opposite of this result, Gebrekirstos (2015) found that there is no significant difference between male and female teachers in experiencing occupational stress. He concluded that gender doesn't play a significant role in contributing experience of occupational stress. Gebrekirstos (2015) emphasize that the reason gender may not show a statistically significant difference in experiencing occupational stress is due to the same mechanism used both male and females in coping occupational stress. The researcher suggested possible explanations for the gender difference may be due to the female teachers' experienced different workloads and tasks besides the teaching settings. Besides, male and female teachers may apply different stress coping mechanisms.

\section{Relationship between personality types and occupational stress}

As presented in the finding section, personality type (extraversion, neuroticism, agreeableness, and conscientiousness) has a significant relationship with the occupational stress of teachers. Specifically, there was a positive correlation between neuroticism and the occupational stress of teachers. But there was a weak and statistically insignificant relationship between openness and occupational stress.

Similar results found by O'Connor (2015) and reported a strong positive correlation between stress and neuroticism. The finding also indicated that there is a moderate negative correlation between conscientiousness and occupational stress and between extraversion personality dimension and occupational stress. But the current finding of this study is not similar to the results of the regression analysis result which was found by O'Connor (2015) that revealed that occupational stress was predicted by neuroticism.

The current finding is in line with a study conducted by Paola, Anna, and Barrano (2015) and who found a significant link between personality and occupational stress. In particular, the result shows that neuroticism is positively associated with occupational stress and which is similar to the present finding. Contrary to the current finding Paola, Anna, and Barrano (2015) found that the three personality types (extraversion, agreeableness, and conscientiousness) did not show a statistically significant relationship with occupational stress. And the openness to experience dimension is also found a significant link with occupational stress which is contrary to current findings.

Other study finding by Asmawati et al. (2014) in their study of the relationship and influence of personality on job stress among academic administrators at a National University of Malaysia also confirmed the present study result. They found that there is a statistically significant association between personality and occupational stress. Further, the finding of the study indicated that there is a positive relationship between occupational stress and neuroticism, and a meaningful negative link was found between occupational stress and extraversion which is similar to the result of the recent study.

The present finding replicates the previous study which was conducted by Dahiya (2015). Dahiya (2015) in his study of occupational stress and personality traits in the Indian Manufacturing Sector found that personality 
traits have a significant relationship with occupational stress. The Pearson product-moment correlation analysis revealed that all the five types of personality traits i.e., Extraversion, Agreeableness, Conscientiousness, Neuroticism, and Openness were found to have a significant relationship with the level of occupational stress experienced by employees.

In the present research study, the regression results indicated that personality traits are positively and significantly related to occupational stress and could explain $25.1 \%$ of the variation in occupational stress of PHEIs of Addis Ababa. A study conducted by Dahiya (2015) also found similar results and who stated that the personality types could explain $71.5 \%$ of the variation in the value of occupational stress. He also found that neuroticism is highly responsible for occupational stress which is contradictory to the current research finding.

The previous finding of Madavi (2016) was found similar results with the current study and reported that there is a statistically significant link between extraversion and occupational stress and a statistically insignificant relationship between openness and occupational stress. The finding of the study also found that agreeableness and conscientiousness personality types were not significantly associated with occupational stress which is contrary to the present finding.

The present finding also found that conscientiousness and agreeableness personality types predict occupational stress of teachers significantly. This result is in line with previous studies (Asmawati et al.; Dahiya, 2015; and Madavi, 2016). The implication of this finding suggests that individuals with conscientious and agreeableness personality traits are less exposed to occupational stress because they are well organized and solve stressful situations calmly and in pleasant mood.

The current findings are consistent with the person-environment fit model that guides my thesis work which was developed by the cooperation of different scholars predominantly the work of Kahn, French, Caplan, and Van Harrison (Hassard \& Cox, 2015). The theory suggests that mismatch between the individuals' capacity and environmental demands create occupational stress. The finding of the study also revealed that various teachers are working in contradiction with their personality, capacity, and interest. This gradually leads teachers to experience different psychological problems like boredom, difficulty concentrating at work, easily irritated, dissatisfaction with their work, and avoid smooth communication with their colleagues.

\section{SUMMARY, CONCLUSION, and RECOMMENDATION'S}

\section{Summary}

The main objective of this study was to examine the link between personality types and occupational stress of teachers in PHEIs of Addis Ababa. To arrive at the intended objectives, the study was guided by the following basic research questions.

What is the level of occupational stress of teachers?

Is there any significant difference between male and female teachers in experiencing stress?

Is there any significant relationship between big five personality type and occupational stress of teachers?

To address the research questions, a correlational research design was applied. The population of this study consisted of a total of 250 teachers who are currently working in private higher educations of Addis Ababa and a total of 154 participants were selected as a sample. Out of this 118 male and 27 female teachers properly filled and returned the questionnaire.

Both descriptive and inferential statistics were applied in analyzing the data. To examine the link between personality types and occupational stress Pearson-product moment correlation was used. An independent samples t-test was used to observe the difference in the experiencing occupational stress of male and female teachers.

The first research question addressed the issue related to the proportion of teachers who experienced occupational stress of teachers in private higher education institutions of Addis Ababa. The result of the study revealed that only $26.9 \%$ of teachers teaching at private higher learning institutions in Addis Ababa experienced a high level of occupational stress.

The analysis of independent samples t-test found that the mean occupational stress scores of male and female teachers were found 47.7 and 57.74, with SDs of 11.24 and 5.24 respectively. The t-test yielded a statistically significant difference between the mean scores of male and female teachers on the overall occupational stress scale $(\mathrm{df}=143, \mathrm{t}=-4.491, \mathrm{P}=.000, \alpha=0.05)$.

The correlation analysis of the study revealed that there is a statistically significant negative correlation between occupational stress and conscientiousness $(\mathrm{r}=-0.442, \mathrm{p}<0.05)$, agreeableness and occupational stress $(\mathrm{r}=$ $-0.371, \mathrm{p}<0.05)$, and extraversion and occupational stress $(\mathrm{r}=-0.347, \mathrm{p}<0.05)$. However, there is no statistically significant relationship between openness and occupational stress of teachers $(r=-0.002, p>.05)$. There was a significant positive correlation between neuroticism and the occupational stress of teachers $(r=0.211, p<0.05)$. Moreover, the results revealed that personality has a statistically significant and negative association with occupational stress $(\mathrm{r}=-0.338, \mathrm{p}<0.05)$. However, only two of the personality dimensions which were conscientiousness $(r=-0.244, p=0.014, \alpha=0.05)$ and agreeableness $(r=-0.193, p=0.027, \alpha=0.05)$ predicted 
occupational stress significantly.

\section{Conclusion}

Based on the result of the study, the researcher concluded the following points.

The prevalence of occupational stress among teachers of PHEIs is nearly $27 \%$.

There is a statistically significant difference between male and female teachers in experiencing occupational stress. The findings of the study found that the mean score of female teachers is higher than compared of male teachers.

The analysis of Pearson product-moment correlation shows that there is a statistically significant association between personality types and occupational stress except openness to experience dimension $(\mathrm{p}<0.05)$.

\section{Recommendations}

The following recommendations are suggested by the researcher:

For PHEIs the significant relationship between 4 personality types (i.e. conscientiousness, agreeableness, extraversion, and neuroticism) and occupational stress is helps to understand the nature of the variables. With understanding about such an outcome, teachers could possibly reduce their occupational stress by developing and aligning their personality type with the occupational settings.

Based on findings of the study, employing individuals with conscientiousness and agreeableness personality dimensions could influence and predicts the level of occupational stress. So, school administrates and human resource should ensure that they identify the personality type of applicants before they made any recruitment and selection decision.

In this study, the relationship between personality types and occupational stress of teachers were tried to be examined. Future research should extend the variables like salary, working conditions, age, experience, qualification, position, and educational reforms into consideration.

The current research was conducted in PHEIs only. So, future researchers should emphasize private and government education institutions.

\section{REFERENCES}

Abiy, T. (2014). Work-related stress and coping strategies of ministry of defence central command referral hospital military health workers.

Aftab, M. (2013). An Investigation into the relationship among teacher's occupational stress, job satisfaction, work values, and pupil control ideology. Aligarh Muslim University,

Agai-Demjaha, T., Bislimovska, J.K., \& Mijakoski, D. (2015). Level of work-related stress among Teachers in Elementary Schools. Journal of Medical Sciences, 3(3), 484-488. doi.org/10.3889/oamjms.2015.076

Ahghar, G. (2008). The role of school organizational climate in occupational stress among secondary school teacher in Tehran. International Journal of Occupational Medicine and Environmental Health, 21(4), 319329.

Ahmad, N., \& Ashraf, M. (2016). The impact of occupational stress on university employees' personality. Journal of Education and Educational Development, 3(2). Available at SSRN: https://ssrn.com/abstract=2942161

Alemu, Y., Teshome, A., Kebede, M., \& Regassa, T. (2014). Experience of Stress among Student-Teachers Enrolled in Postgraduate Diploma in Teaching (PGDT): The Case of Haramaya University Cluster Centers, Ethiopia. African Educational Research Journal, 2(3), 96-101.

Ambachew. T. (2014). Birth Order Personality and Academic Achievement Motivation Among Addis Ababa University. Addis Ababa University, Ethiopia.

Amsalu, N. (2018). Assessment of job-related stress and its predictors among nurses working in government hospitals of West Shoa Zone, Oromia region, Ethiopia

Aniţei, M., Stoica, I., \& Samsonescu, M. (2013). Particularities of personality traits and perceived stress at the workplace for the young workers in Romania. Procedia-Social and Behavioral Sciences, 84, 1010-1014. doi: 10.1016/j.sbspro.2013.06.690

Antoniou, A.S, Polychroni, F., \& Vlachakis, A.N. (2006). Gender and age differences in occupational stress and professional burnout between primary and high-school teachers in Greece. Journal of Managerial Psychology, 21(7), pp. 682-690. doi: 10.1108/02683940610690213

Asmawati, D., Fatimah, Y., Norhayati, I., Nor Ba'yahA, k., \& Roseliza, M.R. (2014). A study of the relationship and influence of personality on job stress among academic administrators at a National University of Malaysia: Journal of Social and Behavioral Sciences, 114, 355 - 359. doi: 10.1016/j.sbspro.2013.12.711

Baraza, O.T., Simatwa, E.M., \& Gogo, J.O. (2016). Levels of Stress among Secondary School Teachers and its Implication on Students' Academic Performance in Kenya: A Case Study of Kakamega North Sub County. Greener Journal of Educational Research, 6(2), 052-066. doi: 
http://doi.org/10.15580/GJER.2016.2.032816069.

Barkhuizen, N. \& Rothmann, S. (2008). Occupational stress of academic staff in South African higher education institutions. South African Journal of Psychology, 38(2), pp.321-336.

Batista, L.C. (2017). The relationship between occupational stress and instigator workplace incivility as moderated by personality: a test of an occupational stress and workplace incivility model. Florida International University Electronic Theses and Dissertations. doi: 10.25148/etd. fidc001942

Baysaka, B., \& Yener, M.I. (2015). The relationship between perceived leadership style and perceived stress on hospital employees: Journal of Social and Behavioral Sciences, 207, 79 - 89. https://doi.org/10.1016/j.sbspro.2015.10.159

Boyle, G.J., Borg, M.G., Falzon, J.M., \& Baglioni, A.J. (1995). A structural model of the dimensions of teacher stress. British Journal of Educational Psychology, 65 (1), 49-67: ISSN 2044-8279.

Browne, R. H. (1995). On the use of a pilot sample for sample size determination. Statistics in Medicine, 14(17), 1933-1940. doi:10.1002/sim.4780141709

Chan, H.S., Chen, K., \& Chong, Y.L. (2010). Work Stress of Teachers from Primary and Secondary Schools in Hong Kong. Proceedings of the International Multi conference of Engineers and Computer Scientists, 3, March 17-19, 2010 Hong Kong.

Colomeischi, A. A. (2015). Teachers` Burnout in Relation with Their Emotional Intelligence and Personality Traits. Journal of Social and Behavioral Sciences 180, 1067 - 1073. doi: 10.1016/j.sbspro.2015.02.207

Costa, P. T., Jr., \& McCrae, R. R. (2017). The Revised NEO Personality Inventory (NEO-PI-R). The NEO Personality Inventory. Psychological Assessment, 2, 223-257. doi:10.4135/9781849200479.n9

Dahiya, S. (2015). Occupational Stress and Personality Traits in the Indian Manufacturing Sector: An Analytical Study. Journal of Human Resource Management and Organisational Behaviour, 1(2). doi: 10.16962/EAPJHRMOB/issn.2394-0409

Darge, W. (2002). The predominance of different sources of stress among teachers in government senior high schools of Addis Ababa. The Ethiopian Journal of Education, 12(1).

Dawson, B.Y. \& Thompson, N.J. (2017). The Effect of Personality on Occupational Stress in Veterinary Surgeons. JVME 44(1). doi: 10.3138/jvme.0116-020R

Desai, U. \& Pandya, K. (2017). Measuring impact of personality traits on level of work stress among employees of Insurance Industry. Stress Management Professional an International Journal, 5(1), 64-71.

Dessalegn, H.A, Abebe, D.A., Bekele, T.M., Benalefew, L.M., Berhanu, D.T. (2016). Assessment of Occupational Stress and Associated Factors among Nurses in East Gojjam Zone Public Hospitals Northwest Ethiopia. Clinical Medicine Research, 6(2), pp. 43-48. doi: 10.11648/j.cmr.20170602.13

Dhar, N. \& Magotra, R. (2018). A Study of Occupational Stress among Teachers Teaching in JKBOSE \& CBSE in Jammu District: A Comparative Study. International Journal of Advanced Research in Education \& Technology (IJARET), 5(1)

Dumitru, V.M. \& Cozman, D. (2012). The relationship between stress and personality Factors. International Journal of the Bioflux Society, 4(1).

Elleni, K., (2017). Job satisfaction of teachers in some selected secondary schools of Addis Ababa (Master thesis, Addis Ababa $\quad$ University). Retrieved from https://pdfs.semanticscholar.org/d26f/15740a06ca76c63541ed4af84676f1d9fc4c.pdf

Gatchel, R.J. \& Schultz, I.Z. (2012), Handbook of Occupational Health and Wellness, 23 Handbooks in Health, Work, and Disability. doi: 10.1007/978-1-4614-4839-6_2,

Gebrekirstos, H. A. (2015). Occupational stress among secondary school teachers and their coping strategies: The case of central zone of Tigray region. International Journal of Academic Research in Education and Review, 3(6), 143-157.

Gezae, G., Walelegn, W., Getahun, K., \& Ararso, T. (2018). Work Related Stress among Health Care Workers in Mekelle City. An International Peer-reviewed Journal of Health, Medicine and Nursing, 46

Ghani, M. Z., Ahmad, A. C., \& Ibrahim, S. (2014). Stress among special education teachers in Malaysia. Procedia-Social and Behavioural Sciences, 114, 4-13.

Gurpreet, R. (2009). Teachers Stress Search for the Right Vision. NICE Journal of Business, 4(1), 1-7.

Hasan, A. (2014). A study of occupational stress of primary school teachers. Educationia Confab, 3(4).

Hassard, J., \& Cox, T. (2015). Work-related stress: Nature and management. London: Birkbeck.

Hatti, S., B., Aneelraj, Kalita, K. N., \& Baruah, A. (2016). Occupational stress of school teacher's working in government and private schools. International Journal of Medicine Research, 1(5), 53-55.

Herman, K.C, Prewitt, S.L., Eddy, C.L, Savale, A., \& Reinke, W.M. (2020). Profiles of middle school teacher stress and coping: Concurrent and prospective correlates. Journal of School Psychology 78, 54-68. https://doi.org/10.1016/j.jsp.2019.11.003

Higher Education Relevance and Quality Assurance, (HERQA, 2012). Recognized Private Higher Education Institutions $\quad$ in $\quad$ Ethiopia. $\quad$ Retrieved from 
https://www.google.com/search?q=private+higher+education+institutions\&rlz=1C1CHBD_enET900ET900 \&oq $=$ private + higher $+\&$ aqs $=$ chrome $.3 .69 \mathrm{i} 57 \mathrm{j} 017.11814 \mathrm{j} 1 \mathrm{j} 4 \&$ sourceid $=$ chrome $\& \mathrm{ie}=\mathrm{UTF}-8$

Holeyannavar, P. G., \& Itagi, S. K. (2010). Stress and health status of primary school teachers. Karnataka Journal of Agricultural Sciences, 23(4), 620-624.

International Labor Organization. (2002). Work place stress: A collective challenge. ILO Publications, Geneva.

Ipek, H., AKcay, A., Atay, S.B., Berber, G., Karalik, T., \& Yilmaz, T.S. (2018). The Relationship Between Occupational Stress and Teacher Self-Efficacy: A Study with EFL Instructors. Anadolu Journal of Educational Sciences International, 8(1), 126-150. DOI: 10.18039/ajesi.393945

John, O. P., \& Srivastava, S. (1999). The Big Five trait taxonomy: History, measurement, and theoretical perspectives. Handbook of personality: Theory and research, 2, 102-138.

Jude, A.M. (2011). Emotional intelligence, gender and occupational stress among secondary school teachers in Ondo state, Nigeria. Pakistan Journal of Social Science, 8(4), pp. 159-165

Kabito, G.G. \& Wami, S.D. (2020). Perceived work-related stress and its associated factors among public secondary school teachers in Gondar city: a cross-sectional study from Ethiopia. BMC Research Notes, 13(36). https://doi.org/10.1186/s13104-020-4901-0

Kaur, S. (2011). Comparative Study of Occupational Stress among Teachers of Private and Govt. Schools in Relation to their Age, Gender and Teaching Experience. International Journal of Educational Planning \& Administration, 1(2), 151-160.

Kebelo, K.K \& Ananda Rao, T.V. (2012). Role stressors as predictors of psychological strain among academic officers of Ethiopian Higher Education Institutions. Journal of the Indian Academy of Applied Psychology, $38(2), 367-373$.

Khurshid, F., Butt, Z. H., \& Malik, S. K. (2011). Occupational role stress of the public and private sector universities teachers. Language in India: Strength for today and Bright Hope for Tomorrow, 11. Kothari, C.R. (2004). Research methodology: methods and techniques (2 ${ }^{\text {nd }}$ revised ed.). new Delhi: New Age International Publisher.

Mahdavi, A. (2016). Relationship between Job Stress and Personality Dimensions of Physical Education Teachers in the City of Pars Abad. Business and Economics Journal, 7(245). doi: 10.4172/21516219.1000245

Maxwell, A.R. (2012). The Relationship between Occupational Stress and Job Satisfaction among High School Teachers in the North Metropole District in the Western Cape (Master thesis, Western Cape University).

Meaza, T. (2018). Assessment of Job Stress in Selected Branches of Commercial Bank of Ethiopia (Master thesis, ST. Mary's University). Retrieved from http://197.156.93.91/bitstream/123456789/4330/1/Meaza\%20Teshome.pdf

Melisa, E.K., Bulent, A., \& Meral, E. (2016). Effects of family-work conflict, locus of control, self-confidence and extraversion personality on employee work stress. Procedia - Social and Behavioral Sciences, 235, 269 $-280$

Mmaduakonam, A. \& Ifeoma, O.E. (2015). Personality traits as determinants of stress among secondary school teachers in Anambra state. European Scientific Journal, 11(11).

Morris C. (2015). The Connection between Personality Traits and Perceived Stress: An in-depth look at how personality traits can influence perceived stress during an immersion study in a developing nation (Master's thesis, Indian university). Retrieved from https://scholarworks.iu.edu/dspace/handle/2022/19998

Nagra, V. \& Arora, S. (2013). Occupational stress and health among teacher educators. International Journal of Advanced Research in Management and Social Sciences, 2(8). ISSN: 2278-6236

O'Connor, N. (2015). The correlation among personality characteristics, stress, and coping of caregivers of individuals with intellectual and developmental disabilities. Walden Dissertations and Doctoral Studies.

Ozutku, H. \& Altindis, S. (2011). Big five personality factors and other elements in understanding work stress of Turkish health care professionals. African Journal of Business Management, 5(26), 10462-10473. doi: 10.5897/AJBM11.2110 ISSN 1993-8233

Paola, M., Anna, P., \& Barrano, C. (2015). Relationships between personality and burn-out: an empirical study with helping professions' workers. International Journal of Humanities and Social Science Research, 1, 1019.

Pithers, R.T \& Soden, S. (2006). Person-environment fit and teacher stress. Educational Research, 41(1), 5161.doi: 10.1080/0013188990410105

Polit, D. F., \& Beck, C. T. (2006). The content validity index: Are you sure you know what's being reported? critique and recommendations. Research in Nursing \& Health, 29(5), 489-497. doi:10.1002/nur.20147

Popoola, B. I. \& Ilugbo, E. A. (2010). Personality traits as predictors of stress among female teachers in Osun state teaching service. Edo Journal of Counseling, 3(2), 173-188.

Raza A (2012). Relationship between Occupational stress and job satisfaction of faculty: The case of universities of Punjab. Ali Raza/Elixir Human resource management 43: 6913-6920. 
Reddy, G.L. \& Poornima, R. (2012). Occupational Stress and Professional Burnout of University Teachers in South India. International Journal of Educational Planning \& Administration, 2(2), pp. 109-124

Samad, N. I. A., Hashim, Z., Moin, S., \& Abdullah, H. (2010). Assessment of stress and its risk factors among primary school teachers in the Kiang Valley, Malaysia. Global Journal of Health Science, 2(2), 163-171.

Saravanan, K. \& MuthuLakshmi, K. (2017). A Study on Occupational Stress among Teachers of Higher Secondary Schools in Nagappattinam District. Journal of Teacher Education and Research, 12(2), 144-156. doi: 10.5958/2454-1664.2017.00017.9

Selamawit Zewdu Salilih, MSc; Amanuel Alemu Abajobir, (2014). Work-Related Stress and Associated Factors Among Nurses Working in Public Hospitals of Addis Ababa, Ethiopia: A Cross-sectional Study. Workplace Health \& Safety, 62(8).

Sekaran, U. \& Bougie, R. (2016). Research methods for business a skill-building approach. Chichester, West Sussex: United Kingdom John Wiley \& Sons.

Swider, B., w., \& Zimmerman, R., D. (2010). Born to burnout: A meta analytic path model of personality, job burnout, and work outcomes. Journal of Vocational Behaviour, Vol. 76, pp. 487-506.

Suleman, Q., Hussain, I., \& Jumani, N. B. (2018). Occupational Stress among Secondary School Heads: A Gender Based Comparative Study. Journal of Education and Educational Development, 5(2), 240-258.

Tytherleigh, M.Y., Webba, C., Cooperb, C.L., \& Ricketts, C. (2005). Occupational stress in UK higher education institutions: a comparative study of all staff categories. Higher Education Research \& Development, 24(1), pp. 41-61.

Yilmaz, K. (2014). The Relationship between the Teachers' Personality Characteristics and Burnout Levels. Journal of Anthropologist, 18(3), 783-792.

Zamir, Hina, \& Zamir, 2014). Relationship between Personality and Occupational Stress among Academic Managers at Higher Education Level. Research on Humanities and Social Sciences, 4(7), 21-29.

Zhang. L.F. (2012). Personality traits and occupational stress among Chinese academics. An International Journal of Experimental Educational Psychology, 32(7), 807-820. doi: 10.1080/01443410.2012.746641 